\title{
FIRST RECORD OF TRANSANTARCTIC RELATIONSHIPS IN THE TACHINIDAE (DIPTERA, MUSCOIDEA, CALYPTRATAE)
}

RAUL CORTES

\section{ABSTRACT}

The Trichoprosopini (Tachinidae, Tachininae) from Southerr. Chile are considered in this paper a sister group tribe of the New Zealand Cccisorini, both tribes being parasitic on Scarabaeid larvae. This is a new evidence of transantarctic relationships in the Calyptrate Muscoidea.

While sorting out and identifying with Dr. José Henrique Guimarães, at the Museu de Zoologia da Universidade de São Paulo, a representative collection of Tachinid flies from South Chile, we came across some preliminary conclusions which we deem worthwhile publishing. The specimens studied all come from Latitudes $42^{\circ}$ to $56^{\circ}$ South and Longitudes $72^{\circ}$ to $76^{\circ}$ West, which include the provinces of Chiloé (Island and continent), Aysén and Magallanes, in Southern Chile.

Our attention was directed to the genus Trichoprcsopus Macquart, 1843, and allied genera from Chile. While this genus has always been considered a true Proseninae and indeed shows many characters of a Proseninae (facio-frontal profile longer than broad; short antennae; frontal bristles ending at antennal level; greatly elongated flat and wide epistoma; apical cell closed and long petiolated; bare prosternum, etc.), there exist indications in the literature (Dugdale, 1969) that, according to male genitalia, it would rather represent a member of the Tachininae. The genus is the type of the Tribe Trichoprosopini and ranked in the Proseninae.

Dissections of the male and female genitalia of Trichoprosopus Macquart and the allied Trichoceronia Cortés proved that these genera, and also very likely Stuardomyia Cortés, are definitely Tachininae. Most, if not all, representatives of these genera of Trichoprosopini are known parasites of Scarabaeidae white grubs in the soil, whereas the great majority of the Tachininae and Goniinae parasitize larvae of many different families of Lepidoptera.

Also based on the comparative morphology of the male genitalia and the planidium larvae in the uterus, we believe, furthermore, that the Trichoprosopini most probably represent the "sister-group" of the Occisorini from New Zealand, as characterized by Dugdale (1969) and Given (1945). Both tribes coincide in being parasitic on Melolonthinae scarabaeid larvae. In a forthcoming monograph on the Tachinidae from South Chile we trust to confirm this hypothesis.

The only previous citation of a Tachinid genus that may be common to Chile and New Zealand would be that $r_{i}$ Aldrich (1934) who considered Calcageria Curran, 1972 (from New Zealand) a synonym of Opsophagus Aldrich, 1926 (from Chile and Peru), both being Voriini genera. This synonymy, however, was dissociated by Dugdale (1969) as did Townsend (1936) in his key to the world Voriini.

Other know cases of transantarctic groups (Chile, Argentina, South Brazil vs. Australia and New Zealand) among the Schizophora include: the genus Eleleides Cresson (Drosophiloidea, Ephydridae; Mathis, 1977, 1978); the Teratomyzidae (Nothyboidea; Griffiths, 1972); the Helosciomyzidae (Muscoidea, Sciomyzoinea; Barnes, 1981); the Rhinotoridae (Muscoidea, Anthomyzoinea; Griffiths, 1972); and the Oestridae (Papavero, 1977, on hypothetical grounds).

Retired Graduate Research Professor of Entomulogy, Facultad de Agronomía, Universidad de Chile, Casilla 1004, Santiago, Chile. 


\section{ACKNOWLEDGMENTS}

Study of the Tachinid collection at the Museu de Zoologia da Universidade de São Paulo was made possible through a generous grant (Proc. 2.31.20.617/ 82) from the "Conselho Nacional de Desenvolvimento Científico e Tecnológico" (Brazil) (CNPq). To Drs. José Henrique Guimarães and Nelson Papavero my grateful thanks for discussing and reviewing the manuscript of this paper.

\section{REFERENCES}

Aldrich, J. M., 1934. Tachinidae, in British Museum (Nat. Hist.) Diptera of Patagonia and South Chile 7(1): 1-170.

Barnes, J. K., 1981. Revision of the Helosciomyzidae (Diptera). J. r. Soc. N. Z. 11(1): 45-72, 44 figs.

Dugdale, J. S., 1969. A classification of the New Zealand genera of Tachinidae (Diptera: Cyclorrhapha). N. Z. J. Sci. 12(3): 606-646.

Given, B. B., 1945. Tachinid parasites attacking Melolonthid larvae in New Zealand. Trans. r. Soc. N. Z. 75(3): 321-323.

Griffiths, G. C. D., 1972. The phylogenetic classification of Diptera Cyclorrhapha, 340 pp. Dr. W. Junk N. V., The Hague (Series Entomologica, vol. 8).

Mathis, W. N., 1977. Key to the Neotropical genera of Parydrinae, with a revision of the genus Eleleides Cresson (Diptera: Ephydridae). Proc. biol. Soc. Wash. 90(3): 553-565.

Mathis, W. N., 1978. A Synopsis of the Neotropical Eleleides Cresson (Diptera: Ephydridae). Proc. ent. Soc. Wash. 80(4): 465-472.

Papavero, N., 1977. The World Oestridae (Diptera), mammals and continental drift, 240 pp. Dr. W. Junk Publishers, The Hague (Series Entomologica, vol. 14).

Townsend, C. H. T., 1936. Manual of Myiology 3: 18-20 (key to Prosenid Tribes), pp. 121-124 (key to the Trichoprosopini), 232-238 (key to the Voriini). São Paulo. 